\title{
Spectrofluorimetric Analysis of the Fungicide Carbendazim and Its Metabolite 2-Aminobenzimidazole in Natural Water
}

\author{
Diène Diégane Thiaré1,2*, Abdourakhmane Khonté1, Amadou Diop ${ }^{2,3}$, Alphonse Mendy1, \\ Atanasse Coly1, François Delattre ${ }^{3}$, Mame Diabou Gaye-Seye1, Alphonse Tine ${ }^{1}$ \\ ${ }^{1}$ Laboratoire de Photochimie et d'Analyse (LPA), Faculté des Sciences et Techniques, Université Cheikh Anta \\ Diop, Dakar, Sénégal \\ ${ }^{2}$ Unité de Chimie Environnementale et Interactions sur le Vivant (UCEIV), ULCO, Dunkerque, France \\ ${ }^{3}$ Laboratoire de Chimie Analytique et Bromatologie (LCAB), Faculté de Médecine de Pharmacie et \\ d’Odontologie, Université Cheikh Anta Diop, Dakar, Sénégal \\ Email: ${ }^{\text {thiaredienediegane@yahoo.fr }}$
}

Received 16 May 2015; accepted 23 August 2015; published 26 August 2015

Copyright (C) 2015 by authors and Scientific Research Publishing Inc.

This work is licensed under the Creative Commons Attribution International License (CC BY).

http://creativecommons.org/licenses/by/4.0/

(c) (i) Open Access

\begin{abstract}
A spectrofluorimetric method for the direct analysis of carbendazim [methyl 2-benzimidazole carbamate (MBC)] fungicide and its metabolite 2 -aminobenzimidazole $(2-\mathrm{AB})$ in natural waters is described. Very low limit of detection (LOD) and limit of quantification (LOQ) values of 0.002 $0.06 \mathrm{ng} / \mathrm{mL}$ and $0.006-0.2 \mathrm{ng} / \mathrm{mL}$, respectively, were determined by spectrofluorimetric method with small relative standard deviation (RSD) values $<1 \%$. This spectrofluorimetric method was applied to the determination of $\mathrm{MBC}$ and 2-AB residues in natural waters, with satisfactory recovery values of $(88.5 \%-119.2 \%)$.
\end{abstract}

\section{Keywords}

Carbendazim, 2-Aminobenzimidazole, Water Analysis, Fluorescence, Analytical Method

\section{Introduction}

The carbendazim [methyl 2-benzimidazole carbamate (MBC)] is a fungicide that is introduced to control various vegetable and orchard diseases. MBC has been shown to be the solvolysis product of benomyl [1]-[3], and it is very persistent in water and soils [4] [5]. The studies of MBC residues in the environment have shown a varia-

"Corresponding author.

How to cite this paper: Thiaré, D.D., et al. (2015) Spectrofluorimetric Analysis of the Fungicide Carbendazim and Its Metabolite 2-Aminobenzimidazole in Natural Water. American Journal of Analytical Chemistry, 6, 767-775.

http://dx.doi.org/10.4236/ajac.2015.69073 
tion of half-life time ( $\left.\mathrm{t}_{1 / 2}\right)$ ranging from a 42 to 175 days [4] [5] where photodegradation can be a potential process of the fungicide destruction. MBC is the most widely used active ingredient as systemic fungicide with both protective and curative activities against a wide range of fungal diseases [6]. The fungicide may additionally be found as a potential pollutant of water where it can accumulate, which justifies the great interest to study its presence in natural water. In consequence, it will be interesting to assay the 2-aminobenzimidazole (2-AB) which is a photoproduct of MBC in water [7]. The 2-AB molecule is also a substructure of chemosensor receptors used for selective recognition of anions with an important role in a variety of biological activities [8].

In this work, we are interested to the analysis of MBC and its metabolite 2-AB largely utilized in Senegal in vegetable crops. In order to control and eradicate pests, a great variety of pesticides are applied to both rural and urban zones throughout the world. In Senegal, most of the pulverized antiparasitic compounds are widely utilized in a peri-urban agricultural area, called the "Niayes area", where cultures are practiced during all seasons, and where most fruits and vegetables consumed in Senegal are collected. Because of the number of pesticides utilized in the Niayes area and their persistence, serious problems related to chemical pollution and natural water contamination affect its aquatic ecosystem. In consequence, the development of sensitive, selective and precise analytical methods, able to determine the quantity of pesticide residues present in the environment, is necessary.

It is for this reason that we have undertaken a study on the MBC fungicide and its metabolite 2-AB by fluorescence method and we apply the analytical method to the evaluation of fungicide residues in spiked natural waters collected in the Niayes area.

\section{Materials and Methods}

\subsection{Reagents}

MBC $(98 \% \mathrm{~m} / \mathrm{m})$ and 2-AB (>97\% m/m) were purchased from Sigma-Aldrich Chemical Company (USA) and were used without further purification. Spectroscopic grade solvent including dichloromethane (DCM), acetonitrile and dimethyl sulfoxide (DMSO) were obtained from Sigma Aldrich (France). Ethanol was purchased from Prolabo (France), and borate buffer solutions of different $\mathrm{pH}$ values (4, 7 and 10) were from Cluzeau Info Labo. The chemical structure of benzimidazoles is presented in Figure 1.

\subsection{Apparatus}

All spectral measurements were performed at room temperature with a Varian Cary Eclipse Fluorescence Spectrophotometer interfaced with a microcomputer and processed by software FL-WinLab. Standard quartz fluorescence with a 1-cm path lengths (Labo Moderne, France) were used for measurements and a Pipetman of 10 $1000 \mu \mathrm{L}$ (Gilson, France) was used for dilutions. The non-purgeable organic carbon (NPOC) was measured on Total Organic Analyzer Shimadzu (TOC-VCSH/CSN). The $\mathrm{pH}$ measurements were performed with a Consort pH-meter Model P107. The conductivity was recorded on CDM 92, 2-pole Conductivity Cells Radiometer Analytical.

\subsection{Procedures}

\subsubsection{Solutions Preparation}

Stock standard solutions of the fungicides (191.2 mg/L for MBC and $133.15 \mathrm{mg} / \mathrm{L}$ for 2-AB) were freshly prepared by dissolving the compound in acetonitrile. Serial dilutions were performed to obtain working solutions. All solutions were protected against light with aluminum foil and were stored in a refrigerator at $6^{\circ} \mathrm{C}$ for further use.

\subsubsection{Analytical Measurements}

An aliquot of fungicide working solution was placed in a quartz cuvette, and the fluorescence spectra were recorded at a scanning speed of $600 \mathrm{~nm} / \mathrm{min}$. Fluorescence intensity was monitored at fixed analytical excitation $\left(\lambda_{\mathrm{ex}}\right)$ and emission $\left(\lambda_{\mathrm{em}}\right)$ maximum wavelengths of the fungicide by measuring the spectra height signal. All fluorescence measurements were corrected for the solvent (background) signal with the appropriate blank.

\subsubsection{Preparation of Spiked Natural Water Samples}

Natural water samples were collected in 1.5-L amber glass bottles from natural waters (draining, well waters), 


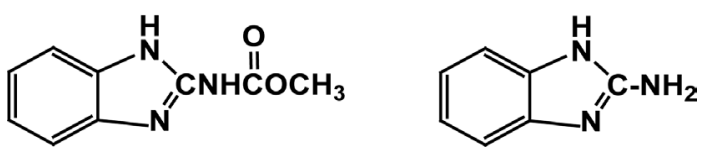

Figure 1. Chemical structure of carbendazim (MBC) and 2-aminobenzimidazole (2-AB).

located inside and on the limits of the agricultural Niayes area. All samples were filtered through a Syringe Filter PTFE membrane, diameter $25 \mathrm{~mm}$ pore size $0.2 \mu \mathrm{m}$ (Sigma-Aldrich) in order to remove any suspended organic matter.

\subsubsection{Solid-Phase Extraction Procedure}

A reversed phase $\mathrm{C}_{18}$ SPE cartridge was conditioned with $5 \mathrm{~mL}$ of acetonitrile taking into consideration keeping the cartridge wet. Then $5 \mathrm{~mL}$ of the spiked water samples $(2,6$ and $10 \mathrm{ng} / \mathrm{mL}$ for MBC or $0.6,1.2$ and 1.8 $\mathrm{ng} / \mathrm{mL}$ for 2-AB) was loaded and the retained compounds were eluted by $4 \mathrm{~mL}$ of acetonitrile. The solid phase extraction method, were able to extract the MBC and 2-AB in the various water samples.

\section{Results and Discussion}

MBC and 2-AB were naturally fluorescent in the different media under study. In order to choose the optimized medium for the fluorescence determination of both pesticides, we decided to investigate the influence of the organic solvent and $\mathrm{pH}$ effect in pure aqueous solvent and we developed afterward, a valid quantitative analytical procedure for the direct spectrofluorimetric determination of MBC and 2-AB after solid-phase extraction (SPE) procedure.

\subsection{Solvent Effect on Excitation and Emission Spectra}

The solvent effect on fluorescence spectra is of particular importance. A change in solvent is accompanied by a change in polarity of the surrounding medium. We have studied the fluorescence emission spectra of MBC and 2-AB in several organic solvents of different polarities and checked the $\mathrm{pH}$ effect in aqueous solutions.

We investigated the fluorescence behaviour of $\mathrm{MBC}$ and its metabolite 2-AB in several solvents of strongly different polarities, including, dichloromethane, ethanol, acetonitrile, DMSO. The results concerning the MBC and 2-AB spectral and chemical properties $\left(\lambda_{\mathrm{ex}}, \lambda_{\mathrm{em}}\right.$ and $\left.\mathrm{I}_{\mathrm{F}}\right)$ in these different media are reported in Table 1 . As can be seen, these spectral and chemical parameters were found to vary more or less importantly with the medium.

The excitation maximum wavelengths presented two main bands in the regions 218 - 260 and 275 - $290 \mathrm{~nm}$, whereas the emission maximum wavelengths occurred in the range $300-323 \mathrm{~nm}$, according to the solvent and the compound (Figure 2 and Table 1). Therefore, taking into account the important changes of solvent polarity, we can consider that the $\lambda_{\text {ex }}$ and $\lambda_{\text {em }}$, values only weakly varied with the medium polarity, except the case of water $(\mathrm{pH}=7)$ for which an important blue-shift of $\lambda_{\text {ex }}$ over than $56 \mathrm{~nm}$ is observed.

The emission band of MBC shows minor variations with increasing solvent polarity; the maximum bathochromic shift being $12 \mathrm{~nm}$. The emission band for $2-\mathrm{AB}$ is more sensitive to solvents and presents a maximum red-shift value of $23 \mathrm{~nm}$ for the different solvents. The fluorescence intensity is much higher in DMSO and acetonitrile than the others media (Table 1). For analytical purposes, DMSO and acetonitrile were chosen as optimal solvents.

On the other hand, the variation of the fluorescence intensity of $\mathrm{MBC}$ and 2-AB as a function of the $\mathrm{pH}$ (curve not shown) was characterized by well defined maximum values of $\mathrm{pH}$ obtained at acid medium for MBC and neutral for 2-AB. The effect of $\mathrm{pH}$ has allowed us to know that the analysis of MBC and 2-AB by fluorescence in water is most appropriate in a strongly acid $(\mathrm{pH}=4)$ and neutral $(\mathrm{pH}=7)$ medium, respectively, for MBC and 2-AB.

\subsection{Analytical Figure of Merit}

In order to select the most interesting conditions from the analytical standpoint, we optimized our spectrofluorimetric method for MBC and 2-AB determination by comparing the $\mathrm{I}_{\mathrm{F}}$ values in the various media under study. Relative to the fungicides fluorescence signal in DCM, which was used as a reference medium, the highest $\mathrm{I}_{\mathrm{F}}$ 

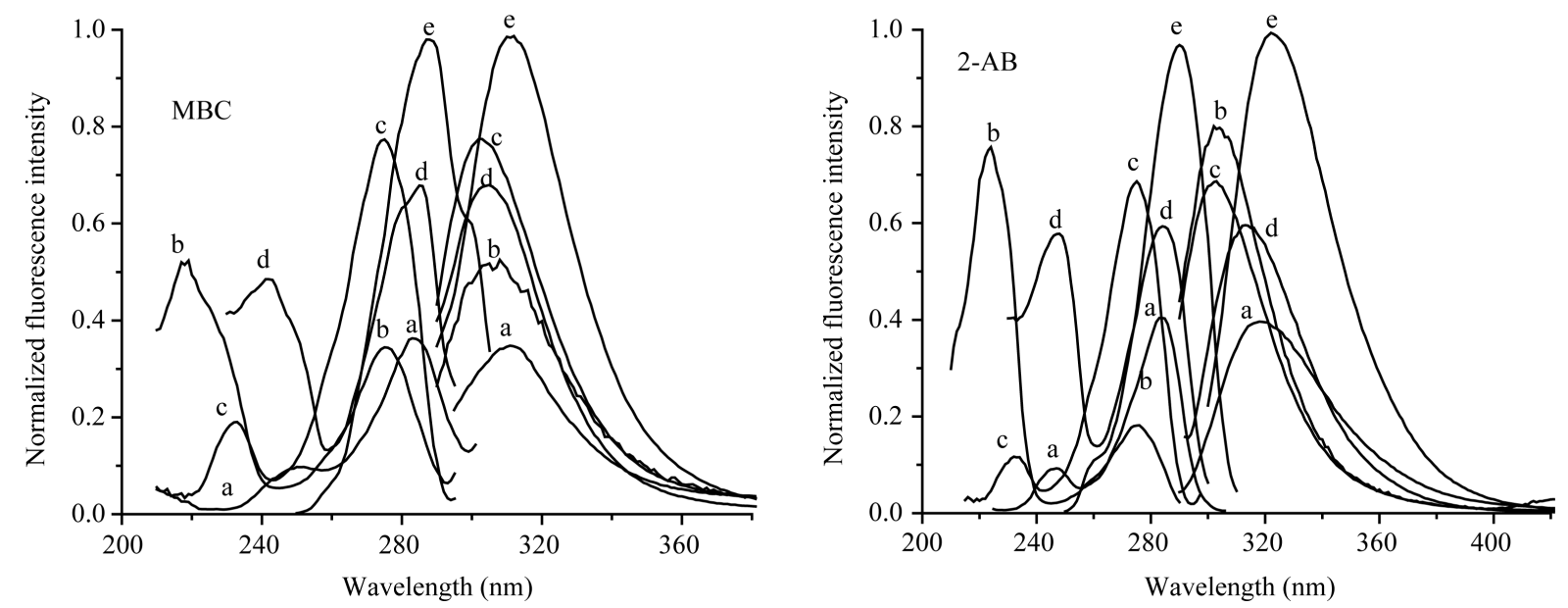

Figure 2. Normalized fluorescence excitation and emission spectra of MBC (4.8 ng/mL) and 2-AB (2.2 ng/mL) in water at different $\mathrm{pH}$ and different organic solvent at room temperature. $\mathrm{pH}=10$ (a), $\mathrm{pH}=7$ (b), $\mathrm{pH}=4$ (c), ethanol (d), and DMSO (e).

Table 1. Optimization of fluorescence parameters of MBC and 2-AB in different solvents.

\begin{tabular}{|c|c|c|c|c|c|c|}
\hline \multirow{2}{*}{ Solvent } & \multicolumn{3}{|c|}{ MBC } & \multicolumn{3}{|c|}{$2-A B$} \\
\hline & $\lambda_{\text {Emax }}^{a}$ & $\lambda_{\text {Fmax }}^{b}$ & $\mathrm{I}_{\mathrm{F}}^{\mathrm{c}}$ & $\lambda_{\text {Emax }}^{a}$ & $\lambda_{\text {Fmax }}^{\mathrm{b}}$ & $\mathrm{I}_{\mathrm{F}}^{\mathrm{c}}$ \\
\hline DCM & 275 & 300 & 1.0 & 275 & 300 & 1.0 \\
\hline Ethanol & 285 & 306 & 3.4 & 284 & 315 & 3.0 \\
\hline Acetonitrile & 285 & 306 & 4.1 & 284 & 314 & 4.2 \\
\hline DMSO & 289 & 312 & 4.8 & 290 & 323 & 4.9 \\
\hline Water $(\mathrm{pH}=7)$ & 218 & 306 & 2.6 & 234 & 303 & 4.0 \\
\hline Water $(\mathrm{pH}=4)$ & 275 & 304 & 3.9 & 275 & 304 & 3.4 \\
\hline Water $(\mathrm{pH}=10)$ & 285 & 311 & 1.7 & 284 & 319 & 2.0 \\
\hline
\end{tabular}

${ }^{\mathrm{a}}$ Wavelength of fluorescence excitation maxima (nm); ${ }^{\mathrm{b}}$ Wavelength of fluorescence emission maxima (nm); ${ }^{\mathrm{c}}$ Relative fluorescence intensity, normalized to the fluorescence intensity in DCM.

values were found in DMSO, acetonitrile and water at $\mathrm{pH}=4$ and 7 . Therefore, for comparison purposes, we decided to evaluate the analytical figures of merit of the fungicide MBC and its metabolite in these selected media, namely DMSO, acetonitrile and in water at $\mathrm{pH}=4$ and 7 (Table 2). Linear plots of fluorescence intensity vs. MBC or 2-AB concentration $I_{f}=f(c)$ were obtained by fluorescence method. The limits of detection (LOD) values were determined on the acetonitrile, DMSO and water $(\mathrm{pH}=4$ and 7) from a MBC and 2-AB concentration giving a signal-to-noise (S/N) ratio of 3 (IUPAC criterion). The limit of quantification (LOQ), is determined for a signal-to-noise $(\mathrm{S} / \mathrm{N})$ ratio of 10 .

The data summarized in Table 2 indicates that linear calibration curves of fluorescence intensity vs. MBC and 2-AB concentration were obtained with large linear dynamic range (LDR) values of about two orders of magnitude, with $r^{2}$ values very close to unity showing a good linearity of the analytical curves. The concentration effect on fluorescence spectra of the MBC and 2-AB in acetonitrile are presented in Figure 3.

The reproducibility of measurements, evaluated with freshly-prepared MBC and 2-AB solutions, was satisfactory, as indicated by the small relative standard deviation (RSD) values less than $1 \%$. The LODs were significantly low, ranging from 0.01 to $0.06 \mathrm{ng} / \mathrm{mL}$ for $\mathrm{MBC}$ and 0.002 to $0.01 \mathrm{ng} / \mathrm{mL}$ for $2-\mathrm{AB}$. The corresponding limit of quantification (LOQ) were $0.03-0.2 \mathrm{ng} / \mathrm{mL}$ for $\mathrm{MBC}$ and $0.006-0.03 \mathrm{ng} / \mathrm{mL}$ for 2-AB (Table 2). 

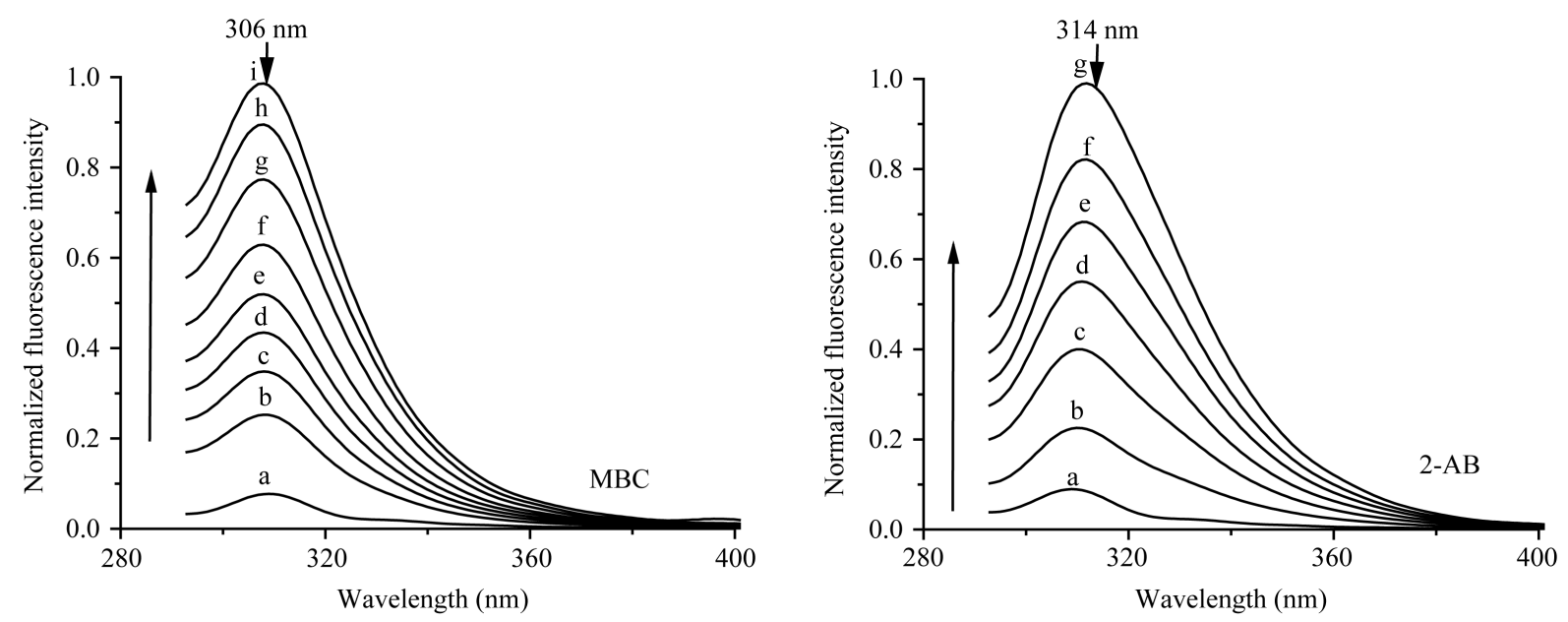

Figure 3. Normalized fluorescence spectra signal of MBC (a: 0.6, b: 1.2, c: 1.8, d: 2.4, e: 3.0, f: 3.6, g: 4.2, h: 4.8, i: 5.4 $\mathrm{ng} / \mathrm{mL}$ ) and 2-AB (a: 0.2, b: 0.6, c: 1.0, d: 1.4, e: 1.8, f: 2.2, g: $2.6 \mathrm{ng} / \mathrm{mL}$ ) in acetonitrile at room temperature.

Table 2. Analytical figure of merit for the determination of MBC and 2-AB.

\begin{tabular}{|c|c|c|c|c|c|c|}
\hline Compound & solvent & LOD $(n g / m L)^{a}$ & LOQ (ng/mL) & LDR $(n g / m L)^{c}$ & $\operatorname{RSD}(\%)^{\mathrm{d}}$ & $r^{2 e}$ \\
\hline \multirow{3}{*}{ MBC } & Acetonitrile & 0.02 & 0.06 & $0.4-20$ & 0.5 & 0.998 \\
\hline & Water $(\mathrm{pH}=4)$ & 0.06 & 0.2 & $0.6-20$ & 0.8 & 0.997 \\
\hline & DMSO & 0.01 & 0.03 & $0.4-20$ & 0.7 & 0.998 \\
\hline \multirow{3}{*}{$2-A B$} & Acetonitrile & 0.005 & 0.02 & $0.1-10$ & 0.6 & 0.997 \\
\hline & Water $(\mathrm{pH}=7)$ & 0.01 & 0.03 & $0.4-10$ & 0.6 & 0.997 \\
\hline & DMSO & 0.002 & 0.006 & $0.1-10$ & 0.7 & 0.998 \\
\hline
\end{tabular}

${ }^{\mathrm{a}}$ Limit of detection was defined as the amount of analyte giving a signal-to-noise ratio of 3 ; ${ }^{\mathrm{b}}$ Limit of quantification defined as the amount of analyte giving a signal-to-noise ratio of 10 ; ${ }^{\mathrm{C}}$ Linear dynamic range; ${ }^{\mathrm{d}}$ Relative standard deviation $(\mathrm{n}=6)$; ${ }^{\mathrm{e}}$ Correlation coefficient.

\subsection{Method Validation}

Our direct fluorimetric method developed, has limits of detection lower than those reported by authors using various methods, such as dispersive liquid-liquid microextraction (DLLME) combined with UV-Vis spectrophotometry (LOD $=2.1 \mathrm{ng} / \mathrm{mL})$ [9], fluorescence method $(0.125 \mathrm{ng} / \mathrm{mL})$ [10], DLLME-HPLC method with fluorimetric detection, $(\mathrm{LOD}=0.5 \mathrm{ng} / \mathrm{mL}$ ) [11], spectrofluorimetric method in hydroxypropyl- $\beta$-CD solutions $(\mathrm{LOD}=17.4 \mathrm{ng} / \mathrm{mL})$ [12], SLM-MMLLE-HPLC with UV detection (LOD $=0.1 \mathrm{ng} / \mathrm{mL})$ [13]. Consequently, the LOD and LOQ values obtained in this work were very low, suggesting that direct fluorescence can be considered as a suitable and sensitive method for determining MBC and 2-AB in natural waters.

\subsection{Choice of Acetonitrile as Packing and Elution Solvent}

Solvent effect has shown that MBC and 2-AB have high fluorescence signal in DMSO, acetonitrile and water $(\mathrm{pH}=4$ and 7). Because of its viscosity, DMSO can neither be used to pack the column nor to elute MBC and 2-AB. The elution of the two benzimidazoles with water $(\mathrm{pH}=4$ and 7$)$ gives also poor percentages of recovery with spectra deformation. As a result, we used acetonitrile as packing and elution solvent to extract the fungicide MBC and 2-AB by SPE.

\subsection{Effect of Elution Solvent Volume}

We studied the effect of the volume of the elution solvent on the extraction efficiency for different volumes of 
the solvent acetonitrile $(0.5,1,2,3,4,5,5.5,6 \mathrm{~mL})$ and the recovery percentage was determined at the same time. Figure 4 illustrates the variation of the extraction recovery versus the volume of the elution solvent. The percentage of recovery was increased with the increase of the volume of elution and became constant when the elution volume of acetonitrile exceeded $4 \mathrm{~mL}$. The maximum elution volume of $4 \mathrm{~mL}$ was chosen to elute the MBC fungicide and its metabolite 2-AB separately.

\subsection{Analytical Applications}

To verify the applicability of the proposed direct spectrofluorimetric method to authentic samples, MBC and 2-AB were determined in natural water samples after a Solid-Phase extraction (SPE) procedure. For recovery studies, $5 \mathrm{~mL}$ of water samples were spiked at three different concentration levels of each pesticide. We used acetonitrile as a packing solvent and as a solvent of elution to extract the fungicide $\mathrm{MBC}$ and 2-AB. Acetonitrile gave good percentage recovery. The results obtained in the different water samples are satisfactory because the recovery rate varies between $88.5 \%$ and $119.2 \%$ (Table 3 ).

On the other hand, the physicochemical parameters of the natural water samples including the dissolved organic carbon NPOC $(\mathrm{mg} / \mathrm{L})$, the conductivity $\sigma(\mathrm{ms} / \mathrm{cm})$ and the $\mathrm{pH}$ (Table 4) seems to play some effects on the MBC and 2-AB recovery. Indeed, after analysis we have noticed that the draining and well waters $(\mathrm{d}=1.5 \mathrm{~m})$ have high recoveries rate relative to the others water samples. The more important recoveries rate in draining water is probably due to the excess of dissolved organic matters (NPOC $=103.5 \mathrm{mg} / \mathrm{L}$ ) which is at least ten or three times more high. The increase of recovery percentage with the amount of dissolved organic matters has been already noted by several authors [14] [15].

Since, the amount of dissolved organic matters in the natural water samples plays a certain role on the rate of recovery of both benzimidazoles, we decided to study the effect of foreign species and of some inorganic ions on the fluorescence intensity of the $\mathrm{MBC}$ in water $(\mathrm{pH}=4)$ and of 2- $\mathrm{AB}$ in water $(\mathrm{pH}=7)$.

\subsection{Interference Studies of Added Foreign Species}

The effect of some pesticides such as benomyl, thiabendazole (commonly-used in Senegal) and several inorganic ions including $\mathrm{Na}^{+}, \mathrm{Ca}^{2+}, \mathrm{K}^{+}, \mathrm{Cl}^{-}, \mathrm{SO}_{4}^{2-}, \mathrm{SO}_{3}^{2-}, \mathrm{CO}_{3}^{2-}$ (likely to exist in natural waters) on the fluorescence intensity was investigated for possible interference on the determination of MBC and 2-AB. We fixed the concentration of $\mathrm{MBC}$ or $2-\mathrm{AB}$, and we evaluated the effect of increase amounts of the interfering species on the fluorescence intensity in appropriate ranges. The tolerance limit of the interfering species was defined as its concentration of which the percentage of fluorescence signal variation did not exceed $\pm 5 \%$ in the determination of MBC and 2-AB. We calculated the percentage of variation of the fluorescence signal, using the following equation for each concentration of interfering species.

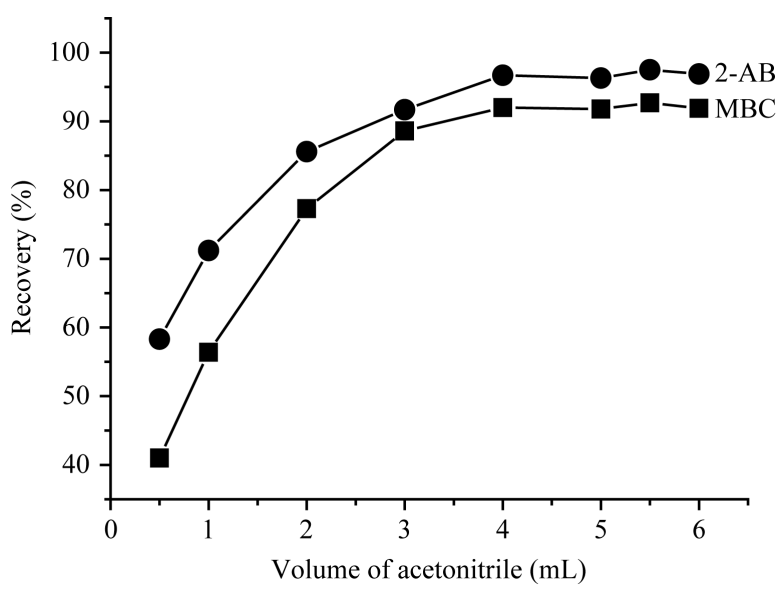

Figure 4. Effect of the volume of elution solvent (acetonitrile) on the extraction recovery of $\mathrm{MBC}$ and 2-AB in well water (depth $<1 \mathrm{~m}$ ). The concentration of fungicides MBC and $2-\mathrm{AB}$ is 6 and $1.2 \mathrm{ng} / \mathrm{mL}$, respectively. 
Table 3. Determination of MBC and 2-AB in natural water.

\begin{tabular}{|c|c|c|c|c|c|c|c|c|}
\hline \multirow{2}{*}{ Matrice } & \multicolumn{4}{|c|}{ MBC } & \multicolumn{4}{|c|}{ 2-AB } \\
\hline & $\begin{array}{l}\text { Added } \\
\text { (ng/mL) }\end{array}$ & $\begin{array}{c}\text { Found }(n=3) \\
(n g / m L)\end{array}$ & $\begin{array}{c}\text { Recovery } \\
\text { (\%) }\end{array}$ & $\begin{array}{c}\text { Mean recovery } \\
\pm \mathrm{SD}\end{array}$ & $\begin{array}{l}\text { Added } \\
\text { (ng/mL) }\end{array}$ & $\begin{array}{l}\text { Found }(\mathrm{n}=3) \\
\quad(\mathrm{ng} / \mathrm{mL})\end{array}$ & $\begin{array}{c}\text { Recovery } \\
\text { (\%) }\end{array}$ & $\begin{array}{c}\text { Mean recovery } \\
\pm \mathrm{SD}\end{array}$ \\
\hline \multirow{3}{*}{$\begin{array}{l}\text { Draining } \\
\text { water }\end{array}$} & 2 & 2.27 & 113.5 & & 0.6 & 0.68 & 113.3 & \multirow{3}{*}{$116.6 \pm 2.4$} \\
\hline & 6 & 6.72 & 112.0 & $111.3 \pm 2.2$ & 1.2 & 1.43 & 119.2 & \\
\hline & 10 & 10.84 & 108.4 & & 1.8 & 2.11 & 117.2 & \\
\hline \multirow{3}{*}{$\begin{array}{l}\text { Well water } \\
(\mathrm{d}=10 \mathrm{~m})\end{array}$} & 2 & 1.86 & 93.0 & & 0.6 & 0.56 & 93.3 & \multirow{3}{*}{$97.2 \pm 3.5$} \\
\hline & 6 & 5.76 & 96.0 & $94.6 \pm 1.2$ & 1.2 & 1.22 & 101.7 & \\
\hline & 10 & 9.47 & 94.7 & & 1.8 & 1.74 & 96.5 & \\
\hline \multirow{3}{*}{$\begin{array}{l}\text { Well water } \\
(\mathrm{d}=1.5 \mathrm{~m})\end{array}$} & 2 & 1.87 & 93.5 & & 0.6 & 0.65 & 108.3 & \multirow{3}{*}{$102.8 \pm 4.1$} \\
\hline & 6 & 5.16 & 106.0 & $96.8 \pm 6.6$ & 1.2 & 1.22 & 101.7 & \\
\hline & 10 & 9.10 & 91.0 & & 1.8 & 1.77 & 98.3 & \\
\hline \multirow{3}{*}{$\begin{array}{l}\text { Well water } \\
(\mathrm{d}<1 \mathrm{~m})\end{array}$} & 2 & 1.77 & 88.5 & & 0.6 & 0.57 & 95.0 & \multirow{3}{*}{$96.5 \pm 1.2$} \\
\hline & 6 & 5.52 & 92.0 & $90.7 \pm 1.5$ & 1.2 & 1.16 & 96.7 & \\
\hline & 10 & 9.15 & 91.5 & & 1.8 & 1.76 & 97.8 & \\
\hline
\end{tabular}

$\mathrm{d}=$ depth of the well water.

Table 4. Physicochemical parameters of the different natural water samples.

\begin{tabular}{cccc}
\hline Water samples & $\operatorname{NPOC}^{\mathrm{a}}(\mathrm{mg} / \mathrm{L})$ & $\sigma^{\mathrm{b}}(\mathrm{mS} / \mathrm{cm})$ & $\mathrm{pH}$ \\
\hline Draining water & 103.50 & 26.25 & 8.17 \\
Well water $(\mathrm{d}=10 \mathrm{~m})$ & 8.99 & 2.91 & 8.24 \\
Well water $(\mathrm{d}=1.5 \mathrm{~m})$ & 29.54 & 2.93 & 6.86 \\
Well water $(\mathrm{d}<1 \mathrm{~m})$ & 9.94 & 2.94 & 7.33 \\
\hline
\end{tabular}

${ }^{\mathrm{a}} \mathrm{NPOC}(\mathrm{mg} / \mathrm{L})=$ dissolved organic carbon, corresponding to the non-purgeable organic carbon present in natural waters. Calculated from the equation: $\mathrm{NPOC}=\mathrm{TOC}-\mathrm{POC}$, with NPOC $=$ non-purgeable organic carbon, TOC $=$ total organic carbon and POC $=$ purgeable organic carbon; ${ }^{\mathrm{b}} \sigma(\mathrm{mS} / \mathrm{cm})=$ conductivity of the water samples.

$$
\Delta F=\frac{F-F_{0}}{F_{0}} \times 100
$$

The tolerance limit obtained for the selected foreign species are presented in Table 5. Fixed concentrations of $2 \mathrm{ng} / \mathrm{mL}$ of $\mathrm{MBC}$ and $0.6 \mathrm{ng} / \mathrm{mL}$ of 2-AB were used to evaluate the effects of interference for the concentration ranges of selected foreign species surrounding the concentrations of $\mathrm{MBC}$ and of 2-AB.

An increase or decrease in intensity was observed during the addition of pesticides or inorganic ions in the studied concentration range. The observed phenomenon may be due to direct interactions between foreign species (pesticides or inorganic ions) with MBC or 2-AB. Our results showed that all tested foreign species have interference on the MBC and the 2-AB. The most important effect of interference on the MBC was observed with benomyl (tolerance limit $=0.05 \mathrm{ng} / \mathrm{mL}$ ) and 2-AB (tolerance limit $=0.07 \mathrm{ng} / \mathrm{mL}$ ). For the 2-AB, the effect of the higher interference was observed with benomyl (tolerance limit $=0.06 \mathrm{ng} / \mathrm{mL}$ ) and $\mathrm{MBC}$ (tolerance limit $=0.06 \mathrm{ng} / \mathrm{mL}$ ). These limits correspond to concentrations about 40 times lower than that of MBC and 10 times 
Table 5. Interference study of foreign species with MBC and 2-AB.

\begin{tabular}{|c|c|c|c|c|}
\hline \multirow{2}{*}{ Foreign species } & \multicolumn{2}{|c|}{ Interference with MBC } & \multicolumn{2}{|c|}{ Interference with 2-AB } \\
\hline & $\begin{array}{l}\text { Tested concentration } \\
\text { range }(\mathrm{ng} / \mathrm{mL})\end{array}$ & $\begin{array}{l}\text { Tolerance limit } \\
\quad(\mathrm{ng} / \mathrm{mL})\end{array}$ & $\begin{array}{l}\text { Tested concentration } \\
\text { range }(\mathrm{ng} / \mathrm{mL})\end{array}$ & $\begin{array}{l}\text { Tolerance limit } \\
\text { (ng/mL) }\end{array}$ \\
\hline MBC & ----- & ---- & $0.01-1$ & 0.06 \\
\hline $2-A B$ & $0.02-4$ & 0.07 & ----- & ----- \\
\hline Benomyl & $0.02-4$ & 0.05 & $0.01-1$ & 0.06 \\
\hline Thiabendazole & $0.02-4$ & 0.1 & $0.01-1$ & 0.09 \\
\hline $2 \mathrm{~K}^{+} \mathrm{SO}_{4}^{2-}$ & $0.05-4$ & 1.8 & $0.05-1$ & 0.4 \\
\hline $\mathrm{Ca}^{2+} 2 \mathrm{Cl}^{-}$ & $0.05-4$ & 1.2 & $0.05-1$ & 0.1 \\
\hline $2 \mathrm{Na}^{+} \mathrm{CO}_{3}^{2-}$ & $0.05-4$ & 1.6 & $0.05-1$ & 0.5 \\
\hline $2 \mathrm{Na}^{+} \mathrm{SO}_{3}^{2-}$ & $0.05-4$ & 1.9 & $0.05-1$ & 0.7 \\
\hline $\mathrm{Na}^{+} \mathrm{Cl}^{-}$ & $0.05-4$ & 1.3 & $0.05-1$ & 0.4 \\
\hline
\end{tabular}

lower than that of 2-AB. These results can be explained by the fact that benomyl is a compound that is metabolized to MBC during ordinary analytical procedures in organic solvents and water [2] [16] [17]. The 2-AB is also a metabolite of MBC, and the three benzimidazoles emit at the same wavelength region. These relatively high interference phenomena require a significant improvement in selectivity when applying the fluorescence method to determine the $\mathrm{MBC}$ and 2-AB in the natural water samples containing the interfering species (pesticides or organic ions). To reduce the impact of the effects of interference and improve the selectivity of the fluorescence method, we believe it would be possible to use spectral method including synchronous fluorescence [18] derivative fluorescence [19] or partial least-square (PLS) method [20].

\section{Conclusion}

We have shown the usefulness of the effect of organic solvent and $\mathrm{pH}$ for improving the sensitivity of the florescence detection of MBC and 2-AB. In this work, we developed a simple, sensitive and precise fluorescence method for the determination of fungicide MBC and its metabolite 2-AB in Senegal natural water samples. Excellent analytical results have been obtained, which permit to detect and quantify MBC and 2-AB at very low concentrations, in the ng/L range, with satisfactory recovery values in natural water samples.

\section{Acknowledgements}

Diène Diégane Thiaré would like to thanks the Service of Cooperation and Cultural Action of the Embassy of France for financial support during his stay in the University of the Littoral Côte d'Opale at Dunkerque (France).

\section{References}

[1] Itak, J.A., Selisker, M.Y., Jourdan, S.M., Fleeker, J.R. and Herzog, D.P. (1993) Determination of Benomyl (as Carbendazim) and Carbendazim in Water, Soil, and Fruit Juice by a Magnetic Particle-Based Immunoassay. Journal of Agricultural and Food Chemistry, 41, 2329-2332. http://dx.doi.org/10.1021/jf00036a021

[2] Garcia-Sanchez, F. and Aguilard-Gallardo, A. (1994) Fluorimetric Determination of the Fungicide Benomyl after Solvolysis. Microchimica Acta, 116, 211-218. http://dx.doi.org/10.1007/BF01260367

[3] Seo, Y.C., Kim, K.D. and Kim, N.J. (2002) Analysis of Benomyl by Liquid Chromatography/Time-of-Flight Mass Spectrometry and Its Occurrence in the Environment. Bulletin of the Korean Chemical Society, 23, 432-436. http://dx.doi.org/10.5012/bkcs.2002.23.3.432 
[4] Cuppen, J.G.M., Van den Brink, P.J., Camps, E., Uil, K.F. and Brock, T. (2008) Impact of the Fungicide Carbendazim in Freshwater Microcosms. II. Zooplankton, Primary Producers of Final Conclusions. Aquatic Toxicology, 48, $233-250$. http://dx.doi.org/10.1016/S0166-445X(99)00036-3

[5] Fernandez, M., Rodriguez, R., Pico, Y. and Manes, J. (2001) Liquid Chromatographic-Mass Spectrometric Determination of Postharvest Fungicides in Citrus Fruits. Journal of Chromatography A, 912, 301-310. http://dx.doi.org/10.1016/S0021-9673(01)00576-3

[6] Tomlin, C.D.S. (2003) The Pesticide Manual. 13th Edition, British Crop Protection Council, UK.

[7] Boudina, A., Emmelin, C., Baaliouamer, A., Grenier-Loustalot, M.F. and Chovelon, J.M. (2003) Photochemical Behaviour of Carbendazim in Aqueous Solution. Chemosphere, 50, 649-655. http://dx.doi.org/10.1016/S0045-6535(02)00620-3

[8] Moon, K.S., Singh, N., Lee, G.W. and Tang, D.O. (2007) Colorimetric Anion Chemosensor Based on 2-Aminobenzimidazole: Naked-Eye Detection of Biologically Important Anions. Tetrahedron, 63, 9106-9111. http://dx.doi.org/10.1016/j.tet.2007.06.091

[9] Pourreza, N., Rastegarzadeh, S. and Larki, A. (2015) Determination of Fungicide Carbendazim in Water and Soil Samples Using Dispersive Liquid-Liquid Microextraction and Microvolume UV-Vis Spectrophotometry. Talanta, 134, 24-29. http://dx.doi.org/10.1016/j.talanta.2014.10.056

[10] Picón Zamora, D., Martínez Vidal, J.L., Martínez Galera, M., Garrido Frenich, A., López González, J.L. and Arahal, M.R. (2003) Correction of Predicted Concentration in the Use of Solvent-Based Calibration Lines for Determining Carbendazim, Fuberidazole and Thiabendazole in Water after a SPE Step. Talanta, 60, 235-344. http://dx.doi.org/10.1016/S0039-9140(03)00065-1

[11] Wu, Q., Li, Y., Wang, C., Liu, Z., Zang, X., Zhou, X. and Wang, Z. (2009) Dispersive Liquid-Liquid Microextraction Combined with High Performance Liquid Chromatography-Fluorescence Detection for the Determination of Carbendazim and Thiabendazole in Environmental Samples. Analytica Chimica Acta, 638, 139-145. http://dx.doi.org/10.1016/j.aca.2009.02.017

[12] Pacioni, N.L., Sueldo-Occello, V.N., Lazzarotto, M. and Veglia, A.V. (2004) Spectrofluorimetric Determination of Benzimidazolic Pesticides: Effect of p-Sulfonatocalix[6]arene and Cyclodextrins. Analytica Chimica Acta, 624, 133-140. http://dx.doi.org/10.1016/j.aca.2008.06.022

[13] Sandahl, M., Mathiasson, L. and Jönsson, J.A. (2000) Determination of Thiophanate-Methyl and Its Metabolites at Trace Level in Spiked Natural Water Using the Supported Liquid Membrane Extraction and the Microporous Membrane Liquid-Liquid Extraction Techniques Combined On-Line with High-Performance Liquid Chromatography. Journal of Chromatography A, 893, 123-131. http://dx.doi.org/10.1016/S0021-9673(00)00697-X

[14] Adamou, R., Coly, A., Abdoulaye, A., Soumaila, M., Moussa, I., Ikhiri, K. and Tine, A. (2011) Photochemically-Induced Fluorescence Dosage of Non-Fluorescent Pyrethroid (Etofenprox) in Natural Water Using a Cationic Micellar Medium. Journal of Fluorescence, 21, 1409-1415. http://dx.doi.org/10.1007/s10895-010-0824-9

[15] Jaffrennou, C., Stephan, L., Giamarchi, P., Cabon, J.Y., Burel, L. and Bautin, F. (2007) Direct Fluorescence Monitoring of Coal Organic Matters Released in Seawater. Journal of Fluorescence, 17, 564-572. http://dx.doi.org/10.1007/s10895-007-0216-y

[16] Thiaré, D.D., Khonté, A., Sarr, D., Diop, C., Gaye-Seye, M.D., Coly, A., Delattre, F., Tine, A. and Aaron, J.J. (2014) Solvolysis Kinetic Study and Direct Spectrofluorimetric Analysis of the Fungicide Benomyl in Natural Waters. Macedonian Journal of Chemistry and Chemical Engineering, 33, 237-248.

[17] García-Sánchez, F. and Cruces Blanco, C. (1988) Spectrofluorometric Determination of Pesticide Residue Mixtures by Isodifferential Derivative Spectroscopy. Analytical Chemistry, 60, 323-328. http://dx.doi.org/10.1021/ac00155a010

[18] Yang, H.M., Wang, Y.S., Li, J.H., Li, G.R., Wang, Y., Tang, X., Xue, J.H., Xiao, X.L. and Kang, R.H. (2009) Synchronous Fluorescence Determination of Urinary 1-Hydroxypyrene, -Naphthol and 9-Hydroxyphenanthrene Based on the Sensitizing Effect of $\beta$-Cyclodextrin. Analytica Chimica Acta, 636, 51-57. http://dx.doi.org/10.1016/j.aca.2009.01.039

[19] Coly, A. and Aaron, J.J. (2001) Simultaneous Determination of Binary Mixture of Sulfonylurea Herbicides in Water by First-Derivative Photochemically-Induced Spectrofluorimetry. Journal of AOAC International, 84, 1745-1750.

[20] Coly, A. and Aaron, J.J. (2009) Simultaneous Determination of Sulfonylurea Herbicides Synthetic Binary Mixtures by a Partial Least Square Method Combined with Micellar-Enhanced Photochemically-Induced Fluorescence: Application to Tap Water Analysis. Macedonian Journal of Chemistry and Chemical Engineering, 27, 33-40. 